\title{
Isostructural Transition in RTAl Compounds at High Temperatures
}

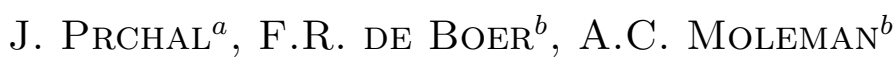 \\ AND P. JAVORSKÝ ${ }^{a}$ \\ ${ }^{a}$ Charles University, Faculty of Mathematics and Physics, DCMP \\ Ke Karlovu 5, 12116 Prague 2, Czech Republic \\ ${ }^{b}$ Universiteit van Amsterdam, Van der Waals-Zeeman Instituut \\ Valckenierstraat 65, 1018 XE Amsterdam, The Netherlands \\ Based on previously discovered forbidden values of the $c / a$ ratio, we \\ studied anomalies in the temperature evolution of the lattice parameters \\ $(a, c)$ of several hexagonal RTAl compounds at high temperatures (above \\ room temperature). The compound $\mathrm{ErNi}_{0.45} \mathrm{Cu}_{0.55} \mathrm{Al}$, that seemed to be im- \\ possible to be prepared in single-phase form, reaches the single-phase state \\ at temperatures above $493 \mathrm{~K}\left(220^{\circ} \mathrm{C}\right)$. On the other hand, the compound \\ $\mathrm{TbNi}_{0.7} \mathrm{Cu}_{0.3} \mathrm{Al}$ - that was expected to undergo a first-order structural \\ phase transition at high temperatures - exhibits a second-order type tran- \\ sition when approaching the critical values of the $c / a$ ratio. These results \\ are in agreement with idea of a forbidden range of $c / a$ values in these com- \\ pounds.
}

PACS numbers: 61.50.Ks, 61.05.cp

\section{Introduction}

For several RTAl compounds $(\mathrm{R}=$ rare earth; $\mathrm{T}=$ transition metal $)$ crystallizing in the hexagonal ZrNiAl-type of structure, an anomalous behavior of the lattice parameters has been observed. A step in the temperature and composition dependence of the lattice constants $a$ and $c$ is present in many of these compounds (e.g. TbNiAl [1], GdNiAl [2], TbPdAl [3,1], GdPdAl [4], $\operatorname{ErNi}_{1-x} \mathrm{Cu}_{x} \mathrm{Al}$ [5], $\mathrm{DyNi}_{1-x} \mathrm{Cu}_{x} \mathrm{Al}$ [6], etc.). As a common feature, for all these compounds a first-order type of transition is found in which values of the $c / a$ ratio in the range $c / a \approx 0.565$ to 0.575 are forbidden.

We have studied several compounds exhibiting this type of transition at high temperatures up to $\approx 1270 \mathrm{~K}\left(900^{\circ} \mathrm{C}\right)$ in order to check the possibility of the isostructural transition at high temperatures. We have focused particularly on the $\mathrm{ErNi}_{0.45} \mathrm{Cu}_{0.55} \mathrm{Al}$ and $\mathrm{TbNi}_{0.7} \mathrm{Cu}_{0.3} \mathrm{Al}$ compounds for their specific properties.

Polycrystalline samples were prepared by a standard arc-melting process under Ar-protective atmosphere starting from a stoichiometric composition of the pure elements. The ingots were pulverized, and then checked by means of 
X-ray diffraction technique with the Bragg-Brentano arrangement. The high-temperature measurements were performed using a Nonius powder diffractometer, able to operate at temperatures up to $1270 \mathrm{~K} . \mathrm{A} \mathrm{Cu} K_{\alpha_{1,2}}$ radiation was used as the source beam and the data were refined using the FullProf program [7] with corrections for the instrumental deviations.

\section{Results and discussion}

In the $\mathrm{ErNi}_{1-x} \mathrm{Cu}_{x} \mathrm{Al}$ system, upon varying the $\mathrm{Ni}-\mathrm{Cu}$ ratio, the compound $\mathrm{ErNi}_{0.45} \mathrm{Cu}_{0.55} \mathrm{Al}$ has been found to be at the boundary of the transition [5]. The compound exhibits coexistence of two isostructural phases between room temperature and $8 \mathrm{~K}$ and was originally expected not to exist in single-phase form. In this temperature region, two hexagonal phases (with the same symmetry, differing just in two sets of the $a, c$ parameters and thus having two different values of the $c / a$ ratio) are found (see Fig. 1b). However, the compound is found to become single phase when it is heated up to almost $600 \mathrm{~K}$. When reaching the temperature of $500 \mathrm{~K}\left(\approx 220^{\circ} \mathrm{C}\right)$, one of the phases disappears (see Fig. 1$)$. The reversibility of this
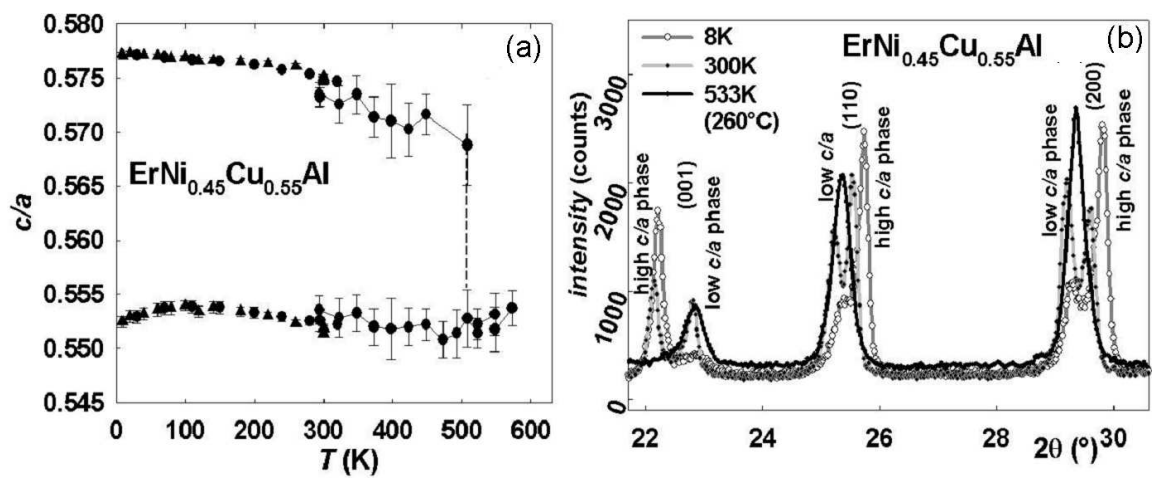

Fig. 1. (a) Temperature dependence of the $c / a$ ratio for $\mathrm{ErNi}_{0.45} \mathrm{Cu}_{0.55} \mathrm{Al}$. (b) Parts of diffraction patterns for selected temperatures. Only one phase is observable in the diffraction pattern at $533 \mathrm{~K}\left(260^{\circ} \mathrm{C}\right)$.

effect (upon cooling the sample below $500 \mathrm{~K}$ it becomes again two-phase) confirms the first-order type transition in this compound and also the nature of forbidden values itself. In comparison with the usual $c / a \approx 0.565$ to 0.575 range, a slight shift of the forbidden values is seen in Fig. 1a. This may be due to a somewhat enhanced disorder in the system at higher temperatures. It should be noted that the shift is small and its determination is difficult because accurate determination of the $a$ and $c$ values of the vanishing phase is difficult due to weakness of the corresponding reflections. Nevertheless, the first-order character of the transition is still evident.

In the pseudoternary series $\mathrm{TbNi}_{1-x} \mathrm{Cu}_{x} \mathrm{Al}$, an isostructural transition has been reported at room temperature between $0.2<x<0.3$ [8], similar to the one 
in the $\mathrm{ErNi}_{1-x} \mathrm{Cu}_{x} \mathrm{Al}$ series at $0.5<x<0.6$. In addition, for $x=0.0(\mathrm{TbNiAl})$ and $x=0.1$ (also for $x=0.2$ ), the same type of transition is observable as a consequence of changing the temperature at about $110 \mathrm{~K}$ and $200 \mathrm{~K}$, respectively (see Fig. 2). Based on the tendency of the transition temperatures with increasing $\mathrm{Cu}$ concentration, a similar first-order type of transition may be expected at higher temperatures for compounds with $x \geq 0.3$. Indeed, we have observed a transition in $\mathrm{TbNi}_{0.7} \mathrm{Cu}_{0.3} \mathrm{Al}$ around $350 \mathrm{~K}$ (see Fig. 2). However, in contrast with the two above-mentioned compounds, the transition in the compound with $x=0.3$ is more smooth, looking like second-order type. The measurement was performed in both temperature regimes - i.e. cooling and heating but no hysteresis could be observed between these two regimes of thermal history.

Two aspects of these data should be discussed. The first is that the $c / a$ ratio of $\mathrm{TbNi}_{0.7} \mathrm{Cu}_{0.3} \mathrm{Al}$ reaches the forbidden values between 0.565 and 0.575 at about $320 \mathrm{~K}$. This may be a consequence of larger disorder in this compound caused by the increased $\mathrm{Cu}$ content. This agrees with the tendency, visible in the lower part of Fig. 2, that the transition becomes broader at higher $\mathrm{Cu}$ content. The second aspect is that the transition happens at similar values of $c / a$, which indicates the criticality of these values.

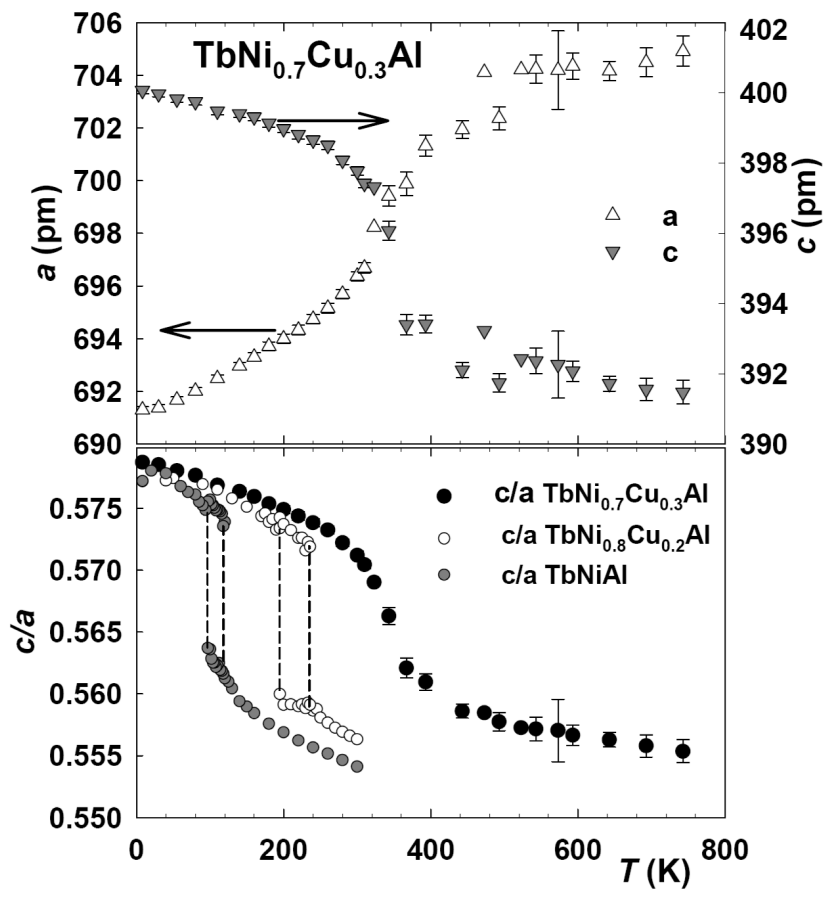

Fig. 2. Temperature dependence of the lattice parameters $a, c$ and the ratio $c / a$ for $\mathrm{TbNi}_{0.7} \mathrm{Cu}_{0.3} \mathrm{Al}$. The $c / a$ data for $\mathrm{TbNiAl}[1]$ and $\mathrm{TbNi}_{0.8} \mathrm{Cu}_{0.2} \mathrm{Al}$ are displayed for comparison. Only data from the cooling regime are included for better lucidity. 
TABLE

The summary of the lattice parameters for the compounds $\operatorname{ErNi}_{0.45} \mathrm{Cu}_{0.55} \mathrm{Al}$ and $\mathrm{TbNi}_{0.7} \mathrm{Cu}_{0.3} \mathrm{Al}$ at specific temperatures below and above the isostructural transition. Symmetry of both compounds for all the temperature range is the same $(P-62 m)$.

\begin{tabular}{c|c|c|c|c|c|c|c}
\hline \hline \multirow{2}{*}{$T[\mathrm{~K}]$} & \multicolumn{4}{|c|}{$\mathrm{ErNi}_{0.45} \mathrm{Cu}_{0.55} \mathrm{Al}$} & \multicolumn{3}{|c}{$\mathrm{TbNi}_{0.7} \mathrm{Cu}_{0.3} \mathrm{Al}$} \\
\cline { 2 - 8 } & $a_{1}[\mathrm{pm}]$ & $c_{1}[\mathrm{pm}]$ & $a_{2}[\mathrm{pm}]$ & $c_{2}[\mathrm{pm}]$ & $T[\mathrm{~K}]$ & $a[\mathrm{pm}]$ & $c[\mathrm{pm}]$ \\
\hline 8 & $698.7(3)$ & $386.0(2)$ & $689.0(1)$ & $397.7(1)$ & 8 & $691.3(1)$ & $400.1(1)$ \\
448 & $704.3(9)$ & $388.9(5)$ & $697.4(1.0)$ & $398.6(7)$ & 280 & $695.7(2)$ & $398.1(1)$ \\
523 & $703.8(9)$ & $388.7(5)$ & - & - & 393 & $701.3(4)$ & $393.4(2)$ \\
573 & $703.5(1.0)$ & $389.5(6)$ & - & - & 743 & $704.9(6)$ & $391.5(3)$
\end{tabular}

\section{Conclusions}

The obtained results are important contributions to our knowledge of the isostructural transition in the hexagonal RTX compounds. The obtained results clearly support the concept of the existence of a forbidden $c / a$ ratio, suggesting that the stability of the crystal structure depends critically on this ratio. However, also considering results obtained on the $\mathrm{Ce}_{1-x} \mathrm{Y}_{x} \mathrm{PdAl}$ series [9], in which the first-order type transition with respect to the composition is observed at room temperature and in which several compounds are found to possess forbidden $c / a$ values, the $c / a$ anomaly is not yet fully understood and further study of similar compounds is needed.

\section{Acknowledgments}

This work is a part of the research plan MSM 0021620834 that is financed by the Ministry of Education of the Czech Republic and was also supported by the Grant Agency of the Czech Republic (grant \# 202/07/P153).

\section{References}

[1] J. Prchal, H. Kitazawa, T. Furubayashi, P. Javorský, K. Koyama, V. Sechovský, Physica B 378-380, 1102 (2006).

[2] F. Merlo, S. Cirafici, F. Canepa, J. Alloys Comp. 266, 22 (1998).

[3] A. Dönni, H. Kitazawa, P. Fischer, F. Fauth, J. Alloys Comp. 289, 11 (1999).

[4] E. Talik, M. Skutecka, J. Kusz, H. Böhm, J. Jarosz, T. Mydlarz, A. Winiarski, J. Alloys Comp. 325, 42 (2001).

[5] J. Prchal, P. Javorský V. Sechovský, M. Dopita, O. Isnard, K. Jurek, J. Magn. Magn. Mater. 283, 34 (2004).

[6] J. Prchal, P. Javorský S. Daniš, K. Jurek, J. Dlouhý, Czech. J. Phys. 54, suppl. D, 315 (2004).

[7] J. Rodriguez-Carvajal, Physica B 192, 55 (1993).

[8] G. Ehlers, Ph.D. Thesis, Berlin 1997.

[9] J. Prchal, H. Kitazawa, O. Suzuki, J. Alloys Comp. 437, 117 (2007). 